\title{
Driving Pressure: The Road Ahead
}

Mechanical ventilation has long been the cornerstone of treatment for acute respiratory failure to facilitate gas exchange while allowing time for the underlying lung injury to heal. However, ventilator-induced lung injury (VILI) may contribute to the morbidity and mortality associated with acute respiratory failure. In recent years, mechanical ventilation strategies have focused on limiting tidal volume and end-inspiratory plateau pressure to prevent VILI from alveolar overdistention. ${ }^{1}$ Nevertheless, even patients receiving mechanical ventilation according to these guidelines may remain at high risk for VILI. ${ }^{2-4}$ Driving pressure has recently been proposed as a new target for lung-protective ventilation based on numerous observational studies that showed associations between lower driving pressure and lower mortality in subjects with ARDS. ${ }^{5-10}$

Driving pressure is easily calculated at the bedside as the plateau pressure minus PEEP, and it reflects the ratio of the tidal volume to the compliance of the respiratory system. Driving pressure is a strong independent predictor of mortality and may be a key mediator of current lungprotective ventilation strategies., ${ }^{5,-10}$ Reductions in tidal volume or increases in PEEP are only associated with improved survival if they concomitantly result in decreases in driving pressure. ${ }^{5}$ Although there is robust physiologic rationale for targeting driving pressure over traditional surrogates of VILI and now a plethora of observational studies that demonstrate an association between driving pressure and mortality, many questions still need to be answered before driving pressure-targeted ventilation can be prospectively evaluated. Especially before embarking on phase III randomized controlled trials of reducing driving pressure, we must know if there are sufficient numbers of

Dr Fan disclosses relationships with Abbott, ALung Technologies, and MC3 Cardiopulmonary. Dr Sahetya has disclosed no conflicts of interest.

Dr Sahetya is supported by the Pearl M Stetler Fellowship Award. Dr Fan is supported by a New Investigator Award from the Canadian Institutes of Health Research.

Correspondence: Sarina K Sahetya MD MHS, Division of Pulmonary and Critical Care Medicine, Johns Hopkins School of Medicine, 1830 E. Monument St, Suite 503, Baltimore MD 21287; e-mail: ssahety1@jhmi.edu.

DOI: $10.4187 /$ respcare. 07226 patients who could potentially benefit, if driving pressure is an adequate surrogate for lung stress and subsequent VILI, and if a mechanical ventilation strategy that lowers driving pressure can be feasibly tested.

\section{See the Original Study on Page 883}

In this issue of Respiratory CARE, Baldomero et al ${ }^{11}$ took the first step in answering these questions by defining the natural range and temporal variability of driving pressure in patients who receive traditional lung-protective ventilation. In a retrospective review of 125 mechanically ventilated subjects, $\sim 60 \%$ of the participants had driving pressures that exceeded a proposed safety limit of $15 \mathrm{~cm} \mathrm{H}_{2} \mathrm{O}^{5,12}$ within the first $8 \mathrm{~h}$ of mechanical ventilation. They also noted temporal driving pressure variability over the first $24 \mathrm{~h}$ of mechanical ventilation, with gradually decreasing driving pressure presumed secondary to progressive lung recruitment from positive pressure ventilation improving lung compliance and treatment of the underlying illness. ${ }^{11}$ Also, they noted intriguing findings regarding driving pressure differences related to sex, body mass index, and the presence of spontaneous respiratory efforts.

Driving pressure is physiologically and mathematically coupled with tidal volume, plateau pressure, and respiratory system compliance. Thus, reductions in tidal volume may be a powerful mechanism for reducing driving pressure. ${ }^{13}$ In the modern low-tidal volume era, the clinical range of driving pressure is not as wide as the ranges found in studies that used higher tidal volumes. ${ }^{12,14}$ Despite this, the results from Baldomero et al ${ }^{11}$ suggest that a majority of patients on mechanical ventilation may be eligible for interventions that attempt to reduce driving pressure, especially important because trial recruitment in critical care can be notoriously difficult. ${ }^{15-17}$ Furthermore, although Baldomero et al ${ }^{11}$ picked a safety threshold of $15 \mathrm{~cm} \mathrm{H}_{2} \mathrm{O}$, results of other studies suggested a threshold effect closer to $13 \mathrm{~cm} \mathrm{H}_{2} \mathrm{O}$, which suggests even more patients than suspected may benefit from a driving pressure-limited strategy. ${ }^{8,9}$ The true safe upper limit of driving pressure is unknown, and different cutoffs should continue to be evaluated prospectively. In reality, driving pressure is a continuous variable, and the lowest driving pressure that can be achieved without consequences from the strategies necessary to achieve it (eg, respiratory acidosis or the need for increased sedation) will 


\section{EDITORIALS}

likely be optimal. Also, the timing and duration for which strict adherence to a driving pressure-limited strategy would continue to lead to benefits, as opposed to potential risks required to maintain a low driving pressure target, remains to be determined.

The investigators also noted a consistently higher driving pressure for participants who were passively breathing than participants who were actively breathing. Active breathing was ascertained retrospectively, but the findings raise important questions regarding the validity of driving pressure as a surrogate for cyclic lung stress and the contribution of patient effort to measurement of driving pressure and VILI in general. As described above, driving pressure represents the stress applied to the respiratory system (lung and chest wall combined) from end-inspiration to endexpiration. In contrast, transpulmonary driving pressure more directly represents the stress applied to the lung and eliminates the variable effects of chest-wall compliance. The interpretation of airway driving pressure as a marker of VILI assumes that alterations in airway pressure are driven primarily by the lung rather than chest-wall mechanics.

However, in some patients with ARDS, chest-wall compliance is decreased due to obesity, ${ }^{18,19}$ fluid loading, ${ }^{20}$ or increased intra-abdominal pressures. ${ }^{19}$ In these patients, changes in driving pressure could represent changes in the compliance of the lung or the chest wall. In addition, in patients with decreased chest-wall compliance, a high driving pressure may overestimate the potential for VILI due to the contribution of the chest wall to high airway pressures. Indeed, in this study by Baldomero et al, ${ }^{11}$ there was a general trend to increased driving pressure that correlated with increased body mass index, which reflected the increased contribution from the altered chest wall rather than more severe lung injury.

Although measuring transpulmonary driving pressure might be preferable to assess lung stress, an estimation of pleural pressure by using esophageal manometry is required, which is not routinely performed in most ICUs due to its laborious nature, as well as several assumptions and limitations associated with the technique. ${ }^{21}$ Alternatively, airway driving pressure is easily and quickly measured at the bedside, without the need for additional equipment or software. Post hoc analyses of 2 previous studies indicate that, for most patients, airway driving pressure adequately correlates with transpulmonary driving pressure and is an adequate surrogate for lung stress. ${ }^{7,8}$ However, further studies that prospectively evaluate the validity of driving pressure as a surrogate for transpulmonary driving pressure and lung stress are essential.

In the past 19 years, mortality from acute respiratory failure and ARDS has declined substantially with the implementation of lung-protective ventilation. However, personalized mechanical ventilation tailored to an individual's underlying lung physiology or phenotype remains a key research priority for the critical care community. ${ }^{22}$ Unfortunately, in recent years, numerous physiologic approaches to mechanical ventilation have not demonstrated superiority over current practices despite encouraging observational or pilot studies, such as in the most recent study of esophageal pressure-guided PEEP titration. ${ }^{23-25}$ However several important differences existed between the pilot study ${ }^{26}$ and the larger, phase II study ${ }^{23}$ with regard to the study population and comparator group, which may explain the difference in the results. Nevertheless, the disappointment in these promising ventilation strategies after translation to larger randomized controlled trials is perhaps the most replicable finding in critical care research to date.

Consequently, we strongly advocate for a deliberate approach to evaluating driving pressure as a target for lungprotective ventilation by starting with high-quality pilot studies designed and refined through prospective qualitative work to optimize a complex mechanical ventilation strategy intended to limit driving pressure. ${ }^{27,28}$ Rather than attempting to determine preliminary effect sizes, pilot studies should be conducted to determine the feasibility and acceptability of a driving pressure-limited mechanical ventilation strategy before progressing to other phases (Fig. 1). Notably, the preliminary phases of testing should be iterative, which al-

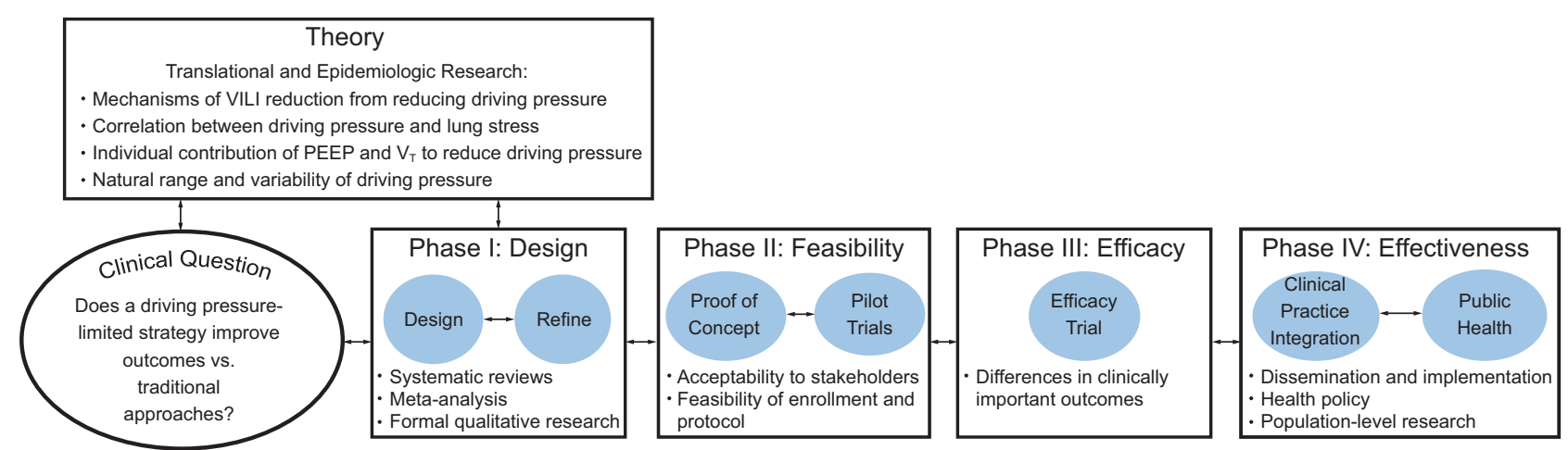

Fig. 1. The continuum of research proposed for evaluating driving pressure as a target for lung protective ventilation strategies in acute respiratory failure. VILI = ventilator-induced lung injury. Adapted from Reference 29. 


\section{EDITORIALS}

lows for bidirectional movement between phases as the intervention is refined and optimized before efficacy testing. The cumulative insights generated from these rigorous pilot studies will be critical to the ultimately successful design and implementation of future efficacy trials. ${ }^{27}$

The road to personalized lung-protective ventilation strategies is currently paved with numerous observational studies that suggest a driving pressure-limited mechanical ventilation strategy could improve outcomes in patients with acute respiratory failure and ARDS. Unfortunately, few prospective studies that target driving pressure as a primary goal for mechanical ventilation have been published at this moment. Perhaps now it is time for the rubber to meet the road.

\section{Sarina K Sahetya \\ Division of Pulmonary and Critical Care Medicine Johns Hopkins School of Medicine \\ Baltimore, Maryland}

\section{Eddy Fan \\ Interdepartmental Division of Critical Care Medicine and the Institute of Health Policy Management and Evaluation University of Toronto Toronto, Ontario, Canada}

\section{REFERENCES}

1. Acute Respiratory Distress Syndrome Network, Brower RG, Matthay MA, Morris A, Schoenfeld D, Thompson BT, Wheeler A. Ventilation with lower tidal volumes as compared with traditional tidal volumes for acute lung injury and the acute respiratory distress syndrome. N Engl J Med 2000;342(18):1301-1308.

2. Grasso S, Stripoli T, De Michele M, Bruno F, Moschetta M, Angelelli G, et al. ARDSnet ventilatory protocol and alveolar hyperinflation: role of positive end-expiratory pressure. Am J Respir Crit Care Med 2007;176(8):761-767.

3. Terragni PP, Filippini C, Slutsky AS, Birocco A, Tenaglia T, Grasso $S$, et al. Accuracy of plateau pressure and stress index to identify injurious ventilation in patients with acute respiratory distress syndrome. Anesthesiology 2013;119(4):880-889.

4. Terragni PP, Rosboch G, Tealdi A, Corno E, Menaldo E, Davini O, et al. Tidal hyperinflation during low tidal volume ventilation in acute respiratory distress syndrome. Am J Respir Crit Care Med 2007;175(2):160-166.

5. Amato MB, Meade MO, Slutsky AS, Brochard L, Costa EL, Schoenfeld DA, et al. Driving pressure and survival in the acute respiratory distress syndrome. N Engl J Med 2015;372(8):747-755.

6. Bellani G, Laffey JG, Pham T, Fan E, Brochard L, Esteban A, et al.; LUNG SAFE Investiga tors; ESICM Trials Group. Epidemiology, patterns of care, and mortality for patients with acute respiratory distress syndrome in intensive care units in 50 countries. JAMA 2016;315(8):788-800.

7. Baedorf Kassis E, Loring SH, Talmor D. Mortality and pulmonary mechanics in relation to respiratory system and transpulmonary driving pressures in ARDS. Intensive Care Med 2016;42(8):1206-1213.

8. Chiumello D, Carlesso E, Brioni M, Cressoni M. Airway driving pressure and lung stress in ARDS patients. Crit Care 2016;20:276.
9. Aoyama H, Pettenuzzo T, Aoyama K, Pinto R, Englesakis M, Fan E. Association of driving pressure with mortality among ventilated patients with acute respiratory distress syndrome: a systematic review and meta-analysis. Crit Care Med 2018;46(2):300-306.

10. Villar J, Martin-Rodríguez C, Domínguez-Berrot AM, Fernández L, Ferrando C, Soler JA, et al.; Spanish Initiative for Epidemiology, Stratification and Therapies for ARDS (SIESTA) Investigators Network. A quantile analysis of plateau and driving pressures: effects on mortality in patients with acute respiratory distress syndrome receiving lung-protective ventilation. Crit Care Med 2017;45(5):843-850.

11. Baldomero AK, Skarda PK, Marini JJ. Driving pressure: defining the range. Respir Care 2019;64(8):883-889.

12. Bugedo G, Retamal J, Bruhn A. Driving pressure: a marker of severity, a safety limit, or a goal for mechanical ventilation? Crit Care 2017;21(1):199.

13. Retamal J, Libuy J, Jiménez M, Deigado M, Besa C, Bugedo G, Bruhn A. Preliminary study of ventilation with $4 \mathrm{ml} / \mathrm{kg}$ tidal volume in acute respiratory distress syndrome: feasibility and effects on cyclic recruitment - derecruitment and hyperinflation. Crit Care 2013; 17(1):R16.

14. Bruhn A, Bugedo D, Riquelme F, Varas J, Retamal J, Besa C, et al. Tidal volume is a major determinant of cyclic recruitment-derecruitment in acute respiratory distress syndrome. Minerva Anestesiol 2011;77(4):418-426.

15. Burns KE, Zubrinich C, Tan W, Raptis S, Xiong W, Smith O, et al.; Canadian Critical Care Trials Group. Research recruitment practices and critically ill patients. A multicenter, cross-sectional study (the Consent Study). Am J Respir Crit Care Med 2013;187(11):1212-1218.

16. Pattison N, Arulkumaran N, Humphreys S, Walsh T. Exploring obstacles to critical care trials in the UK: a qualitative investigation. J Intensive Care Soc 2017;18(1):36-46.

17. Gattinoni L, Vasques F, Quintel M. Use of ECMO in ARDS: does the EOLIA trial really help? Crit Care 2018;22(1):171.

18. De Jong A, Cossic J, Verzilli D, Monet C, Carr J, Conseil M, et al. Impact of the driving pressure on mortality in obese and non-obese ARDS patients: a retrospective study of 362 cases. Intensive Care Med 2018;44(7):1106-1114.

19. Gattinoni L, Chiumello D, Carlesso E, Valenza F. Bench-to-bedside review: chest wall elastance in acute lung injury/acute respiratory distress syndrome patients. Crit Care 2004;8(5):350-355.

20. Verheij J, van Lingen A, Raijmakers PG, Rijnsburger ER, Veerman DP, Wisselink W, et al. Effect of fluid loading with saline or colloids on pulmonary permeability, oedema and lung injury score after cardiac and major vascular surgery. Br J Anaesth 2006;96(1):21-30.

21. Sahetya SK, Brower RG. The promises and problems of transpulmonary pressure measurements in acute respiratory distress syndrome. Curr Opin Crit Care 2016;22(1):7-13.

22. Fan E, Del Sorbo L, Goligher EC, Hodgson CL, Munshi L, Walkey AJ, et al.; American Thoracic Society, European Society of Intensive Care Medicine, and Society of Critical Care Medicine. An Official American Thoracic Society/European Society of Intensive Care Medicine/Society of Crit Care Med Clinical Practice Guideline: mechanical ventilation in adult patients with acute respiratory distress syndrome. Am J Respir Crit Care Med 2017;195(9):1253-1263.

23. Beitler JR, Sarge T, Banner-Goodspeed VM, Gong MN, Cook D, Novack V, et al.; EPVent-s Study Group. Effect of titrating positive end-expiratory pressure (PEEP) with an esophageal pressure-guided strategy vs an empirical high PEEP-Fio2 strategy on death and days free from mechanical ventilation among patients with acute respiratory distress syndrome: a randomized clinical trial. JAMA 2019; 321(9):846-857.

24. Writing Group for the Alveolar Recruitment for Acute Respiratory Distress Syndrome Trial (ART) Investigators, Cavalcanti AB, Suzumura ÉA, Laranjeira LN, Palsani DM, Guimaräes HP, et al. Effect of lung 


\section{EDITORIALS}

recruitment and titrated positive end-expiratory pressure (PEEP) vs low PEEP on mortality in patients with acute respiratory distress syndrome: a randomized clinical trial. JAMA 2017;318(14):1335-1345.

25. Brower RG, Lanken PN, MacIntyre N, Matthay MA, Morris A, Ancukiewicz M, et al.; National Heart, Lung, and Blood Institute ARDS Clinical Trials Network. Higher versus lower positive endexpiratory pressures in patients with the acute respiratory distress syndrome. N Engl J Med 2004;351(4):327-336.

26. Talmor D, Sarge T, Malhotra A, O'Donnell CR, Ritz R, Lisbon A, et al. Mechanical ventilation guided by esophageal pressure in acute lung injury. N Engl J Med. 2008;359(20):2095-2104.
27. Brown SM, Paine R, Lanspa M, Gong M. Value beyond the "P": the case for higher quality and better publicized pilot and feasibility trials. Ann Am Thorac Soc 2019 [Epub ahead of print].

28. Briel M, Olu KK, von Elm E, Kasenda B, Alturki R, Agarwl A, et al. A systematic review of discontinued trials suggested that most reasons for recruitment failure were preventable. J Clin Epidemiol 2016; 80(Can't get issue from record):8-15.

29. Czajkowski SM, Powell LH, Adler N, Naar-King S, Reynolds KD, Hunter CM, et al. From ideas to efficacy: the ORBIT model for developing behavioral treatments for chronic diseases. Health Psychol 2015;34(10):971-982. 